\title{
LSD 'flashback' as a cause of diagnostic error
}

\author{
JEANNe A. SMith \\ B.Sc., M.B., M.R.C.P. (UK)
}

\author{
G. WALTERS \\ M.D., F.R.C.Path.
}

\author{
D. JOHNSTON \\ M.D., F.R.C.S.
}

University Departments of Medicine and Surgery, Bristol Royal Infirmary

\begin{abstract}
Summary
An emaciated, but otherwise physically normal young man presented with an acute pyschosis resembling hallucinogenic drug abuse. His behaviour was so strange that the underlying pathology of severe pyloric stenosis was only detected when a chance measurement of urea and electrolytes was made, revealing gross biochemical abnormalities. His abnormal mental state persisted for more than one week and an LSD 'flashback' was postulated as the cause of the prolonged psychosis.
\end{abstract}

\section{Introduction}

A known hazard to individuals taking lysergic acid diethylamide (LSD) either for therapeutic or psychedelic effects is that of spontaneous recurrences of hallucinations or 'flashbacks'. These may arise many months after ingestion of LSD has ceased and after intervals of complete normality (Smart and Bateman, 1967). Flashbacks are more likely to occur at times of stress (such as sepsis or severe metabolic derangement) and may therefore be precipitated by a totally unrelated illness, the diagnosis of which may be obscured by the prominence of the psychiatric disturbance. The bizarre presentation of the patient described masked his underlying organic disease and initially delayed its diagnosis.

\section{Case report}

A 34-year-old man, a vegan, was referred by his general practitioner who described an acute exacerbation of dyspepsia which had been occurring intermittently for about 2 years. No history could be obtained from the patient but it later transpired that despite his dyspepsia he had been able to continue working as a painter and decorator until 2 weeks previously, and had also travelled 300 miles by train. Since then he had felt increasingly unwell, vomited once or twice daily, and had been taking a belladonna herbal mixture. On admission he was unco-operative, disorientated in space and time, hallucinating and speaking in a slow, depersonalized manner. Clinical examination revealed only cachexia and brisk reflexes. The plantar responses were flexor and there was no muscle weakness. Pulse and BP were normal and abdominal examination showed neither visible peristalsis nor a succussion splash. He vomited only once, some hours after admission. A psychiatric opinion was sought as the patient wanted to discharge himself, and a diagnosis of acute psychosis, probably due to drug ingestion, was made, although the clinical picture was not that associated with belladonna overdosage. However, measurement of plasma urea and electrolytes showed this was only one factor and suggested the presence of pyloric stenosis.

Plasma urea, $75 \mathrm{mmol} / 1$; plasma sodium, 135 $\mathrm{mmol} / \mathrm{l}$; potassium, $1.0 \mathrm{mmol} / \mathrm{l}$; chloride, $33 \mathrm{mmol} / 1$; pH 7.61; $\mathrm{PCO}_{2}, 9.31 \mathrm{kPa}$; standard bicarbonate, $62 \mathrm{mmol} / \mathrm{l}$; base excess, $34 \mathrm{mmol} / \mathrm{l} ; \mathrm{Hb}, 18.1 \mathrm{~g} / \mathrm{dl}$; WCC $25.9 \times 10^{9} / 1$; glucose, $7.0 \mathrm{mmol} / \mathrm{l}$; urine $\mathrm{pH}, 5.0$; urea, $170 \mathrm{mmol} / \mathrm{l}$; sodium, $6 \mathrm{mmol} / \mathrm{l}$; potassium, $55 \mathrm{mmol} / \mathrm{l}$; protein, $3.0 \mathrm{~g} / \mathrm{l}$. Urine microscopy showed occasional casts, a few red and white cells, and was sterile on culture.

Despite the patient's severe dehydration and profound hypokalaemic alkalosis, the only physical abnormality was of hyperreflexia; neither overt nor latent tetany could be elicited. Intravenous fluids were given, rapidly at first, the total in the first $24 \mathrm{hr}$ amounting to 7 litres of normal saline, 4 litres $5 \%$ dextrose, $450 \mathrm{mmol}$ potassium chloride, and 200 mmol ammonium chloride. The oliguria and low ratio of urine urea to plasma urea was thought to be due to acute tubular necrosis secondary to the severe metabolic disturbance (Descamps, Vandenbrouke and Van Ypersele de Strihou, 1977). The mode of recovery was in keeping with this as the plasma urea returned to normal only very slowly, 
despite improvement in the urine volume, following the administration of i.v. frusemide $(250 \mathrm{mg})$ and dialysis was not required. Forty-eight hr after admission, by which time the plasma electrolytes had been restored to normal, the plasma urea was still $62 \mathrm{mmol} / \mathrm{l}$, and his mental state was unchanged. The following day he complained of epigastric pain and passed $500 \mathrm{ml}$ fresh blood mixed with faeces. His behaviour remained odd and irrational, but he eventually consented to endoscopy. This showed a bleeding duodenal ulcer with fresh blood regurgitating through a grossly narrowed pylorus which had produced massive gastric retention. Seven units of blood were transfused and a surgical opinion obtained. A further period of conservative management was advised in view of the patient's strange personality and poor general condition. However, heavy gastro-intestinal bleeding recurred the following day, a further 6 units of blood were transfused and an emergency laparotomy performed. The duodenum was found to be very scarred and there was a large posterior-wall duodenal ulcer and severe narrowing of the pylorus. The stomach was thick walled, greatly dilated and full of fresh blood clot. The ulcer was under-run with Mersilene and a highly selective vagotomy and Finney pyloroplasty performed (by D.J.). Postoperatively, in view of his extreme emaciation, i.v. feeding was initiated with amino acids, lipids, carbohydrates and trace elements. No further complications ensued but the patient's mental state did not begin to improve until 9 days after admission, long after his biochemical changes had returned to normal.

He was discharged home 18 days after admission, taking only ferrous sulphate. Two months later he was eating normally, and had put on $14 \mathrm{~kg}$ in weight. He was graded Visick 2 (very good result) and his mental state was, and has remained, entirely normal since his discharge from hospital.

\section{Comment}

Subsequently, he gave a detailed account of his prolonged psychosis, likening it to a very bad LSD 'trip'. For example, he had thought that his cardiac monitor was a machine through which all his answers to questions were reversed, and he had perceptual distortions of colour and sound, together with paranoid delusions. He had used both LSD and marijuana many times in the past, although the last occasion had been more than one year before ad- $\frac{3}{\mathbb{0}}$ mission, and he admitted to previous LSD flashbacks (2-6 months after drug ingestion). He also $\Rightarrow$ referred to friends who had had similar experiences $\overrightarrow{\vec{s}}$ after taking both LSD and the same belladonnat herbal mixture. Although some of his psychotic symptoms may have been partly attributable to the effects of azotaemia (Stenback and Haapenen, 1967)ब hypokalaemia or hyponatraemia (Arieff, Llach and Massry, 1976; Mendelson and Deza, 1976) they were ${ }^{\infty}$ quite unlike the disturbances sometimes associated $\overrightarrow{0}$ with severe alkalosis or renal failure, and remained $\overrightarrow{-}$ long after correction of his metabolic abnormalities. $\omega$ It is therefore postulated that his acute psychosiso was an LSD flashback precipitated by the stress of 3 his severe biochemical derangement and associated with ingestion of the belladonna mixture.

Although the final outcome was satisfactory, the f authors would like to emphasize that the psychiatric. picture in this patient was so dramatic that initially it completely dominated their thoughts, and had theo urea and electrolytes not been estimated there would certainly have been even more delay in diagnosis and $c$ treatment of his pyloric stenosis. Awareness of the syndrome of LSD flashbacks is therefore important, $\vec{\odot}$ as it may indicate serious underlying physical diseas,$\infty$ and a diligent search for possible precipitating factois. should always be made in patients who present this way.

\section{Acknowledgments}

We thank Dr K. W. Heaton for permission to publish this case.

\section{References}

ARIEFf, A.I., Llach, F. \& MASSRy, S.G. (1976) Neurological manifestations and morbidity of hyponatremia : correlation $\overline{ }$ with brain water and electrolytes. Medicine. Baltimore, 55, 121.

Descamps, C., VANDENBRouke, J.M. \& VAN YPersele de STRIHOU, C. (1977) Rhabdomyolysis and acute tubular necrosis associated with carbenoxolone and diuretic $\frac{\mathrm{O}}{3}$
therapy. British Medical Journal, 1, 272.

Mendelson, W.B. \& DezA, P.C. (1976) Polydipsia, hypo- 응 natremia and seizures in psychotic patients. Journal of Nervous and Mental Diseases, 162, 140.

SMART, B.G. \& BATEMAN, K. (1967) Unfavorable reactions to LSD: a review and analysis of the available case reports. N Canadian Medical Association Journal, 96, 1214.

StenbäCK, A. \& HaApenen, E. (1967) Azotemia and psy- N chosis. Acta psychiatrica et neurologica scandinavica, $43 \mathrm{~N}$ (Suppl. 1), 65. 